\title{
A Modular Approach and Simulation of an Asynchronous Machine
}

\author{
Zineb Mekrini, Seddik Bri \\ Materials and Instrumentation (MIM), High School of Technology, Moulay Ismail University, Meknes, Morocco
}

\begin{tabular}{l}
\hline \hline Article Info \\
\hline Article history: \\
Received Dec 5, 2015 \\
Revised Feb 26, 2016 \\
Accepted Mar 10, 2016 \\
\hline Keyword: \\
abc-qd conversions \\
Asynchronous machine \\
Modeling \\
Speed \\
Torque
\end{tabular}

\begin{abstract}
This article presents the modeling and simulation of the asynchronous machine. The aim of this research is the mastery of the electrical, mechanical and magnetic behaviors of this type of machine. The Matlab/Simulink is used for simulation two types of no-load and additional load services in transitional and permanent operation. The Analytical equations describing the two operating systems are evaluated and developed by a generalized model of a three-phase induction motor. The simulation results presented in this article confirms that the proposed model gave a satisfactory response in terms of torque characteristics and speed.
\end{abstract}

Copyright () 2016 Institute of Advanced Engineering and Science. All rights reserved.

\section{Corresponding Author:}

Zineb Mekrini,

Materials and Instrumentation (MIM),

High School of Technology, Moulay Ismail University,

Meknes, Morocco.

Email: zineb.mekrini@gmail.com

\section{INTRODUCTION}

One of the most common electrical motor used in most applications which is known as induction motor. This motor is also called as asynchronous motor because it runs at a speed less than synchronous speed because the rotating magnetic field which is produced in the stator will generate flux in the rotor which will make the rotor to rotate, but due to the lagging of flux current in the rotor with flux current in the stator, the rotor will never reach to its rotating magnetic field speed [1]-[3].

Energy supplied to the induction motor is distributed in the two parts, the first is in the form of mechanical output and second one is in the form of losses. For the high performance of the motor losses should be small, so the output of motor goes high, Induction motor efficiency is dependent on many motor parameters; however it is a function of the operating speed and applied voltage heir implementation in SIMULINK is outlined [4],[5].

Induction motors constitute a theoretically interesting and practically important class of nonlinear systems. They are described by nonlinear differential equation [5]. The voltage and torque equations that describe the dynamic behavior of an induction motor are time-varying. It is successfully used to solve such differential equations it can thus be modeled by interconnection of appropriate function blocks, each of which performing a specific mathematical operation [6]. A poly phase winding (a,b,c) can be reduced to a set of two phase windings (q-d), the stator and rotor variables (voltages, currents and flux linkages) of an induction machine are transferred to a reference frame, which may rotate at any angular velocity or remain stationary [7]. This article includes the following sections:

- The introduction presents the importance of electrical machines in the economy and the simulation tools used in the field of electrical engineering.

- The theoretical study of the asynchronous machine model. 
- The simulation model in the MATLAB / Simulink.

- The results and discussion.

\section{THEORETICAL ANALYSIS}

This research aimed to investigate whether induction motor operational simulations with general equations could be used for condition monitoring and diagnosis of induction motors. Therefore, a theoretical motor analysis was made based on generalized rotating field theory and by making the following assumptions which are commonly regarded as appropriate [8]:

- The magnetic permeability of iron is considered to be infinite and the air-gap is very small and smooth.

- The state of operation remains far from magnetic saturation.

- The self-inductances and mutual-inductances between stator or rotor phases are constant.

- Mutual-inductances between the stator and rotor windings are functions of the rotor position.

- Space magnetic motive force (MMF) and flux profiles are considered to be sinusoidal distributed and higher harmonics are negligible.

The asynchronous machine is represented by 6 windings 3 in the stator and 3 in the rotor as follows:

$$
\begin{array}{ll}
\mathrm{Vsa}=V m * \cos (2 \pi \mathrm{ft}) & \mathrm{Vra}=V m * \cos (2 \pi \mathrm{ft}) \\
\mathrm{Vsb}=V m * \cos \left(2 \pi \mathrm{ft}-\frac{2 \pi}{3}\right) & \mathrm{Vrb}=V m * \cos \left(2 \pi \mathrm{ft}-\frac{2 \pi}{3}\right) \\
\mathrm{Vsc}=V m * \cos \left(2 \pi \mathrm{ft}-\frac{4 \pi}{3}\right) & \mathrm{Vrc}=V m * \cos \left(2 \pi \mathrm{ft}-\frac{4 \pi}{3}\right)
\end{array}
$$

- Vsa, Vsb and Vsc (V): a-axis, b-axis and c-axis components of the stator voltage vector Vs.

- Vra, Vrb and Vrc (V): a-axis, b-axis and c-axis components of the stator voltage vector Vr.

\subsection{Electrical equation}

The necessary electrical model of the three-phase induction motor was obtained using welldocumented motor models [9]. The matrix form of the stator and rotor voltage equations:

$$
[\mathrm{Vs}]=[R s] *[I s]+\frac{\mathrm{d}[\phi s]}{\mathrm{dt}} \quad[\mathrm{Vr}]=[R r] *[I r]+\frac{\mathrm{d}[\phi r]}{\mathrm{dt}}
$$

The appropriate subscripts as, bs, cs, ar, br, and cr, the voltage equations of the magnetically coupled stator and rotor circuits can be written as follows:

$$
\begin{array}{ll}
\text { Vas }=\text { RsIas }+\frac{\mathrm{d} \phi a s}{\mathrm{dt}} & \text { Var }=\text { RrIar }+\frac{\mathrm{d} \phi a r}{\mathrm{dt}} \\
\mathrm{Vbs}=\text { RsIbs }+\frac{\mathrm{d} \phi b s}{\mathrm{dt}} & \mathrm{Vbr}=\operatorname{RrIbr}+\frac{\mathrm{d} \phi b r}{\mathrm{dt}} \\
\mathrm{Vcs}=\text { RsIcs }+\frac{\mathrm{d} \phi c s}{\mathrm{dt}} & \mathrm{Vcr}=\operatorname{RrIcr}+\frac{\mathrm{d} \phi c r}{\mathrm{dt}}
\end{array}
$$

This mathematical model is a system of six differential equations with coefficients functions periodical of time, resolution is difficult even with the use of the numerical tool.

To remedy this problem we use the three-phase to two-axis voltage transformation. The conversion of a three-phase system $(a, b, c)$ in a two-phase system $(d, q)$ is given by :

$$
\begin{aligned}
& V s d=\sqrt{\frac{2}{3}}\left(V s a-\frac{1}{2} V s b-\frac{1}{2} V s c\right) \\
& V s q=\sqrt{\frac{2}{3}}\left(V s a-\frac{\sqrt{3}}{2} V s b-\frac{\sqrt{3}}{2} V s c\right)
\end{aligned}
$$

In the electrical model, the two-phase voltage [Vds, Vqs, Vdr, Vqr] is the input and the current vector [ids, iqs, idr, iqr] is the output vector. The rotor voltage vector is normally zero because of the shortcircuited cage rotor winding, $\mathrm{Vdr}=0$ and $\mathrm{Vqr}=0$ [10]. 


$$
\begin{aligned}
& V d s=R s * I d s-\omega s \phi q s+\frac{d \phi d s}{d t} \\
& V q s=R s * I q s+\omega s \phi d s+\frac{d \phi q s}{d t} \\
& V d r=R r * I d r-\omega r * \phi q r+\frac{d \phi d r}{d t}=0 \\
& V q r=R r * I q r+\omega r \phi d r+\frac{d \phi q r}{d t}=0
\end{aligned}
$$

- Ids, Iqs (A): d-axis and q-axis components of the stator current vectors Is.

- $\operatorname{Idr}$, Iqr (A): d-axis and q-axis components of the rotor current vectors Ir.

- $\operatorname{Rr}(\Omega)$ : rotor resistance.

- $\operatorname{Rs}(\Omega)$ : rotor resistance.

- $\quad \omega S, \omega r:(\operatorname{rad} / \mathrm{s})$ : stator and rotor Electrical Heartbeat.

- $\phi \mathrm{s}, \phi r$ : stator and rotor fluxes linkage.

\subsection{Magnetic Equation}

In matrix notation, the flux linkages of the stator and rotor windings may be written in terms of the winding inductances and the current in the reference [11]:

$$
\begin{aligned}
& {[\phi \mathrm{s}]=[L s] *[\mathrm{Is}]+[\mathrm{Msr}] *[\mathrm{Ir}]} \\
& {[\phi \mathrm{r}]=[\mathrm{Lr}] *[\mathrm{Ir}]+[\mathrm{Msr}] *[\mathrm{Is}]}
\end{aligned}
$$

- Ls (H): stator inductance.

- $\operatorname{Lr}(\mathrm{H})$ : rotor inductance.

- $\quad \mathrm{M}(\mathrm{H})$ : Mutual Inductance between the stator and the rotor.

- Is, Ir: Stator and rotor currents.

\subsection{Equations of power and torque}

The conversions keep instantaneous power. The last power will be written:

$$
P i=\left[R s * I s d^{2}+R s * I s q^{2}\right]+\left[\frac{d \phi s d}{d t} * I s d+\frac{d \phi s q}{d t} * I s q\right]+\omega s[\phi s d * I s q-\phi s q * I s d]
$$

The first term is easily identifiable in joule losses; the second term corresponds to electromagnetic power; the third term represents therefore the electrical power transformed into mechanical power.In the twoaxis stator reference frame, the electromagnetic torque $\mathrm{Ce}$ is given by:

$$
\begin{aligned}
& P e=C e * \Omega s=\omega s(\phi s d * I s q-\phi s q * I s d) \\
& C e=\frac{P e}{\Omega s}=\frac{\omega s}{\Omega s} *(\phi s d * I s q-\phi s q * I s d) \\
& C e=P *(\phi s d * I s q-\phi s q * I s d) \\
& C e=P * M(I s q * I r d-I s d * I r q)
\end{aligned}
$$

- $\Omega \mathrm{s}(\mathrm{rad} / \mathrm{s})$ : stator angular electrical frequency

- $\mathrm{Ce}(\mathrm{Nm})$ : Electromagnetic torque

- P: Pole number

\subsection{Mechanical Equation}

Mechanical part of induction motor can be described by (9), where is angular rotor velocity, $\mathrm{J}$ - moment of inertia, $\mathrm{Cr}$ - mechanical torque, Ce electromagnetic torque [12].

$$
J . \frac{d \Omega r}{d t}=C e-C r
$$




\subsection{Induction motor slip and efficiency of asynchronous motor}

The motor slip between the swivel field and the rotor is spelt as follows:

$g=\frac{\Omega s-\Omega}{\Omega s}$

The efficiency of the machine varies according to their power is given by:

$$
\eta=\frac{P a}{P u}
$$

- Pa: Absorbed power

- Pu: Output Power

\section{RESULTS AND INTERPRETATIONS}

The induction machine model implemented in this paper is shown in Figure 1. It consists of six major blocks: conversion, abc-dq, induction machine d-q model blocks, Joule stator and rotor losses blocks, slip and efficiency blocks.

The following subsections will explain each block. In this model the simulation starts with generating three-phase stator voltages according to the equations (1), and then transforming these balanced voltages to two phase voltages referred to the using transformation as in equations (4). After that the d-q flux linkage and current equations were implemented as to be demonstrated below as in equations (6). Figure 1 illustrates the internal structure of the induction machine $\mathrm{d}-\mathrm{q}$ model by which the flux linkages, currents, torque and the rotor angular speed are calculated.

The induction motor was the motor of $1.5 \mathrm{KW}$ power and electrical parameters: nominal current, In $3.2 \mathrm{~A}=$ stator resistance $\mathrm{Rs}=5.72 \Omega$, stator inductance $\mathrm{Ls}=0.4642 \mathrm{H}$, rotor resistance, $\mathrm{Rr}=4.2 \Omega$, rotor inductance, $\mathrm{Lr}=0.4612 \mathrm{H}$, mutual inductance $\mathrm{M}=0.44 \mathrm{H}$, the simulation results are given for the induction motor system at different reference speed and load torque: $\mathrm{NS}=1500 \mathrm{tr} / \mathrm{min}$ and $\mathrm{Cr}=12 \mathrm{Nm}$.

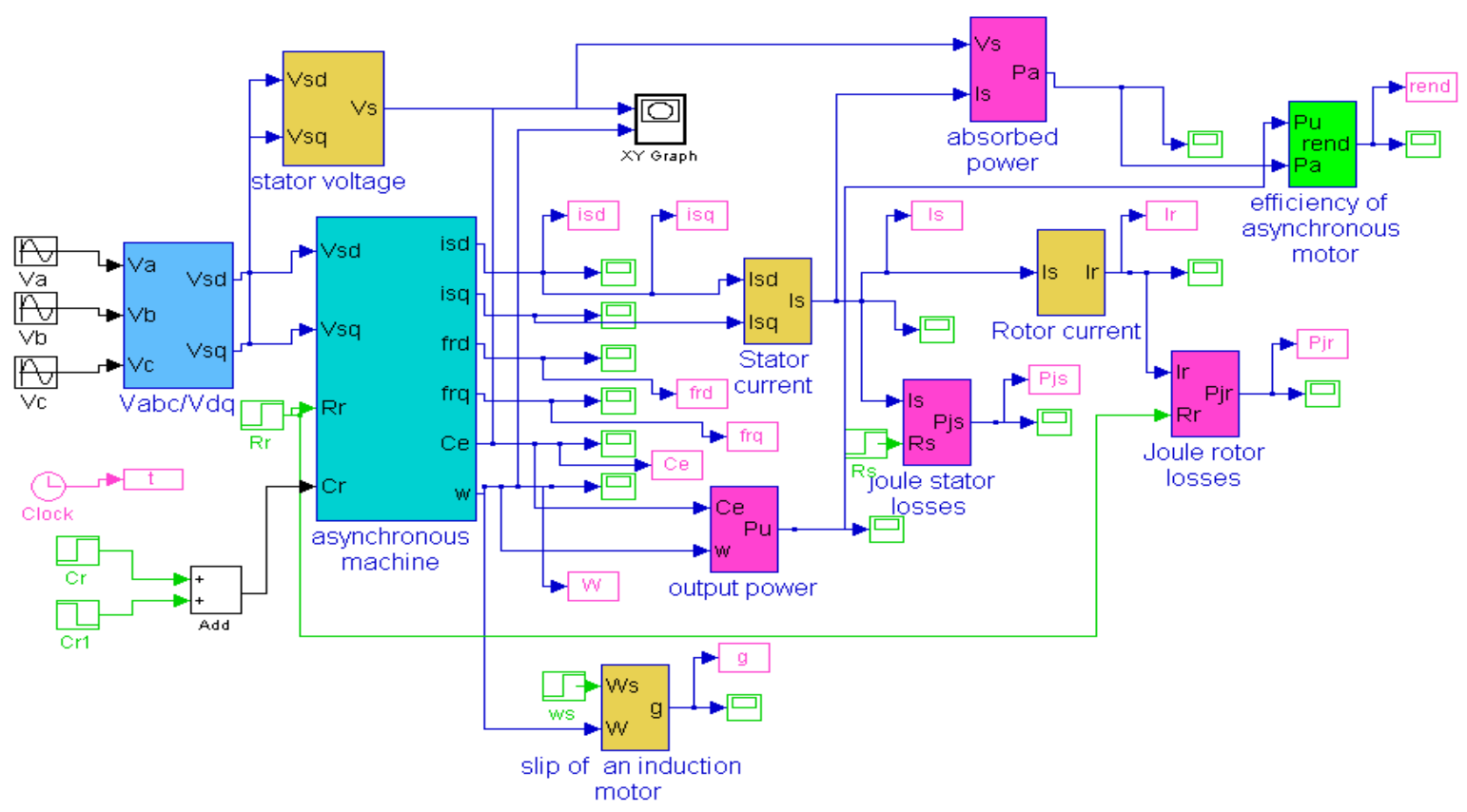

Figure 1. Induction machine dynamic model implementation in Simulink 
The Figure 2 shows the three-phase to two-axis voltage transformation is achieved using the following sub-model:
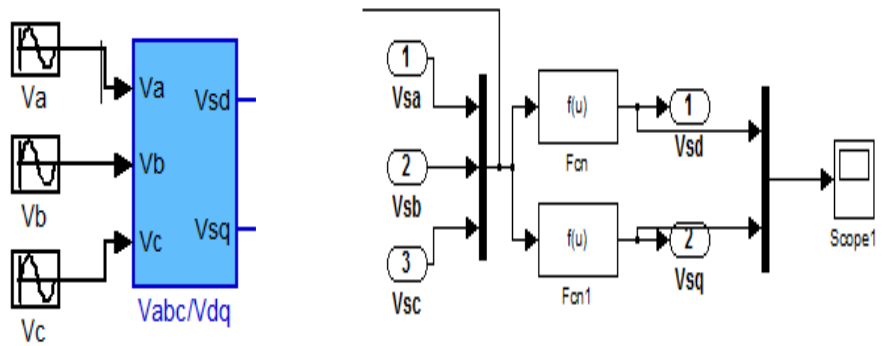

Figure 2. abc-qd conversions

Where Vas, Vbs, and VCs are the three-phase stator voltages, while Vds and Vqs are the two-axis component of the stator voltage vector Vs. The Figure 3 shows the electrical current, flux, torque and rotor speed are represents on the following sub-model of asynchronous machine.

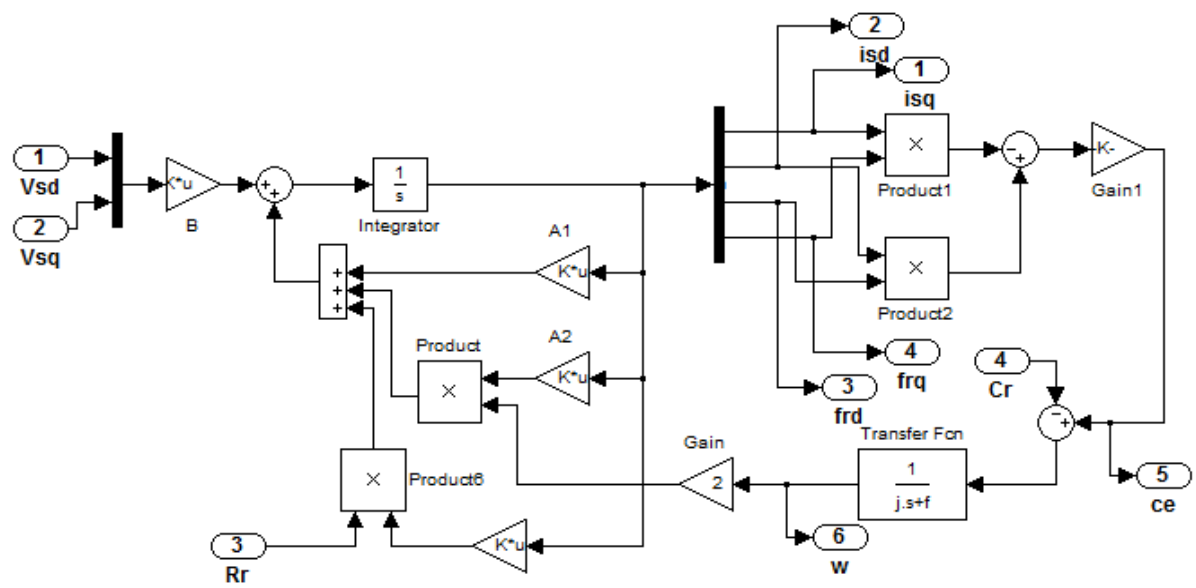

Figure 3. Proposed overall model of an asynchronous machine

The voltage supply block consists of a three-phase sinusoidal voltage generator and the three-phase sinusoidal voltage generator is based on equation (1) and the three phase voltages is modeled as shown in Figure 4.

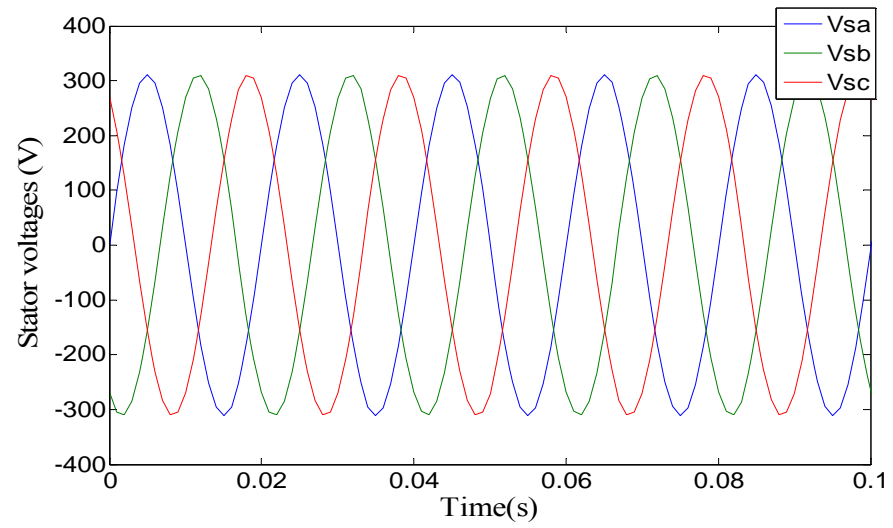

Figure 4. Three-phase stator voltages 
The Figure 5 shows the three-phase to two-axis voltage transformation means the conversion of coordinates from the three phases stationary.

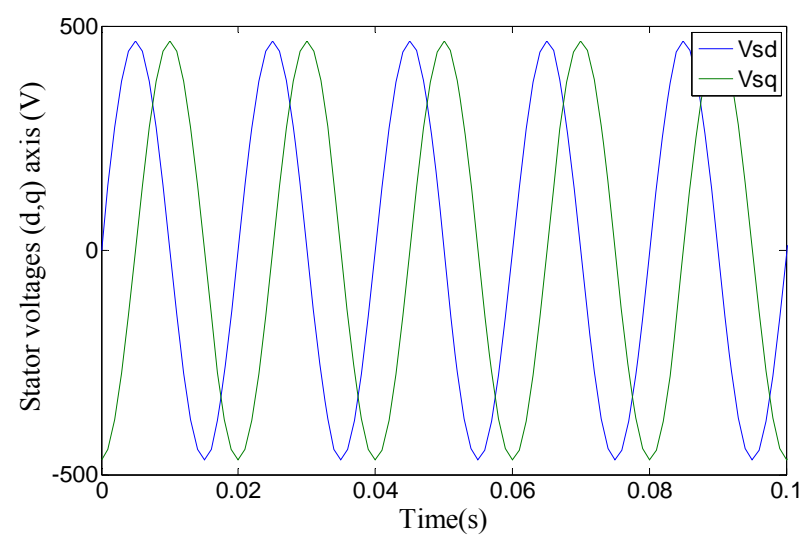

Figure 5. Two -phases' stator voltages

The Figure 6 presents typical waveforms related to start-up of the motor. Motor starts under no-load condition and next, at $\mathrm{t}=1 \mathrm{~s}$ additional load with nominal value was added is $12 \mathrm{Nm}$. Transient simulation during starting of induction motor current is $21.3 \mathrm{~A}$, Almost 6 times the nominal value of the current. The motor has a startup time of approximately $0.2 \mathrm{~s}$ and the starting current is too large [12]. It can be seen from the figure, that the machine has reached steady state at about 0.2 seconds. S. K. Jain, et al [13] observes the starting current is large, in some cases of the order of 10 times the rated value. Therefore, it is recommended that reduced voltage starting methods such as star/delta, auto transformer, and soft start methods be employed to reduce the excess starting current [6]. The application of $12 \mathrm{~N}-\mathrm{m}$ mechanical loads at 1 seconds gives an increase of currents and sharp drop of currents after removal of load at $3 \mathrm{sec}$.

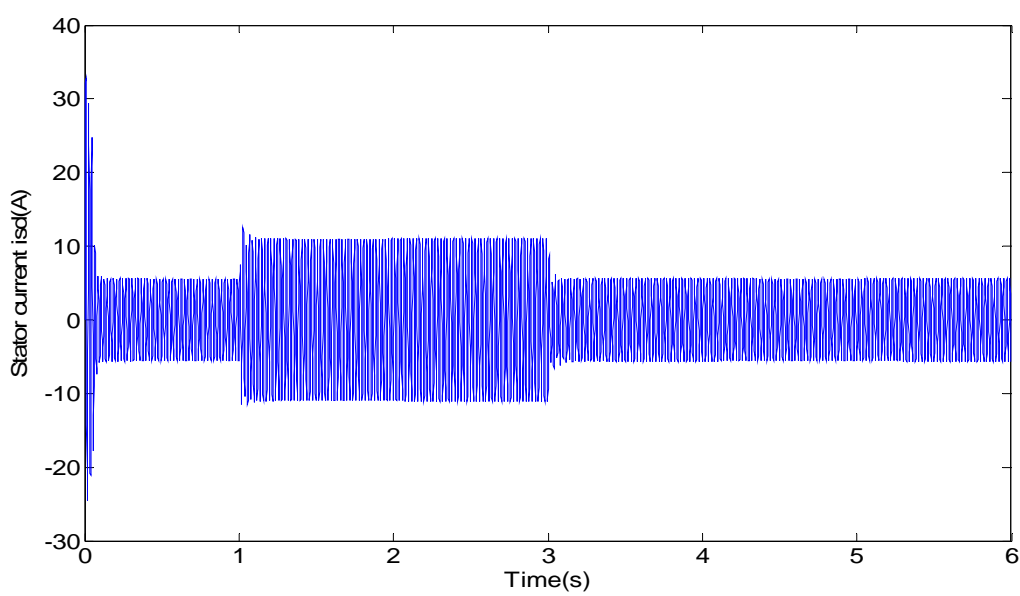

Figure 6. Simulation of induction motor- stator current Isd

The stator current output sub-model is used to calculate the stator current amplitude according to the following Figure 7. After a transient period of $0.2 \mathrm{~s}$; the results stator current varies exponentially until vacuum steady. It is observed from Figure 7 that the stator currents are DC quantities in the steady state at 0.2 sec. The application of $12 \mathrm{~N}-\mathrm{m}$ mechanical loads at 1 seconds as illustrated in Figure 6, results in very slight increase in currents. 


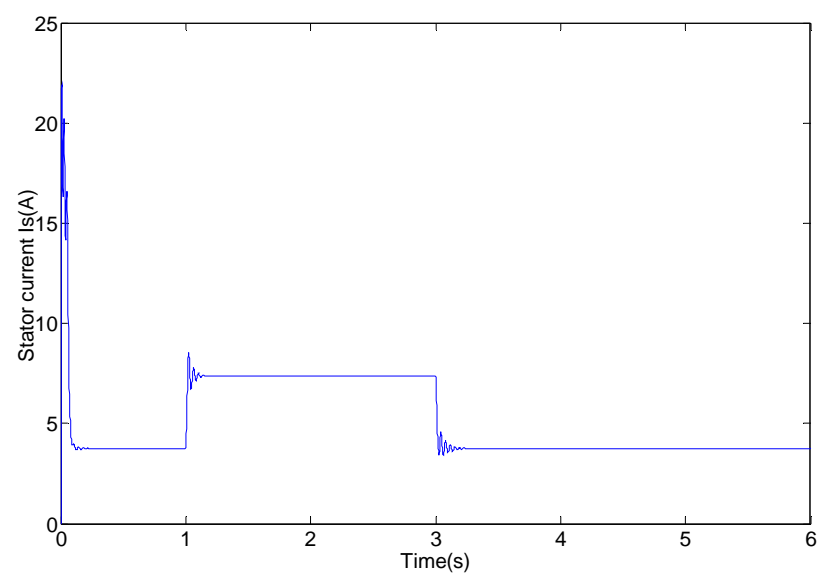

Figure 7. Simulation of induction motor stator current Is

Figure 8 shows the evolution of the mechanical speed during the no-load and coupled load simulation. The speed shows oscillations in the first moments of starting, then stabilizes at a value close to $157 \mathrm{rad} / \mathrm{s}$. since friction and windage losses are not taken into account, the machine accelerates to synchronous speed. It can be seen from figure 8, that the machine has reached steady state at about 0.2 second. The application of $12 \mathrm{~N}$-m mechanical loads at 1 seconds gives a results in sharp drop in the motor speed from $157 \mathrm{rad} / \mathrm{sec}$ to $140 \mathrm{rad} / \mathrm{sec}$ and an increase in After removal of load at $3 \mathrm{sec}$ [13]. Quickly, indicating that MATLAB/Simulink is an appropriate tool to investigate steady-state behavior of induction motors as well, the rotor transient speed variation was been selected as one of the main parameters to be monitored [7],[13].

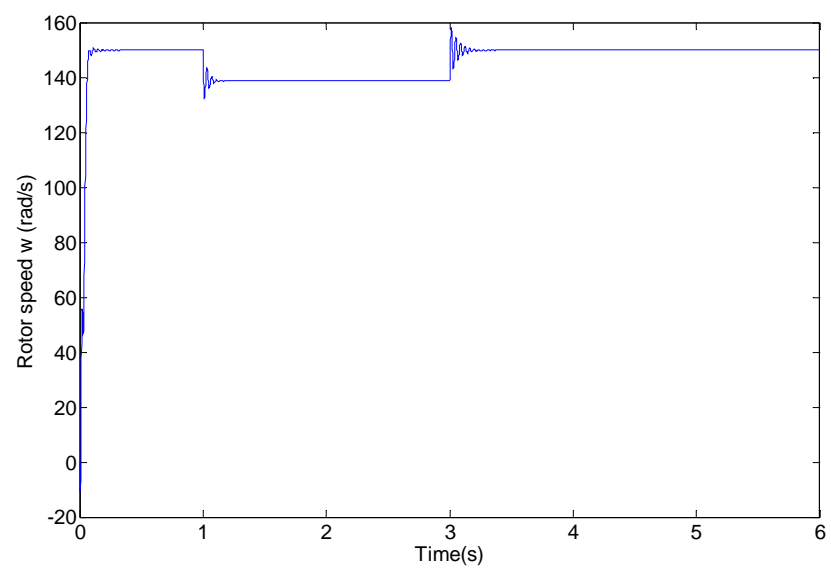

Figure 8. Evolution of the mechanical speed during the no-load and coupled load test simulation

Figure 9 shows the torque calculation from equation (8); it shows as a function of times; however it could also be plotted as a function of speed (Figure 10). The couple has the first moments of starting important beats for a very short time interval, before stabilizing thereafter at a value substantially zero steady. A load torque $(\mathrm{Cr}=12 \mathrm{Nm})$ can be placed on the machine at $\mathrm{t}=1 \mathrm{~s}$ to determine the effect on the acceleration time [13],[14]. An increase in the electromechanical torque upto $24 \mathrm{~N}-\mathrm{m}$ in sympathy with the applied mechanical loading. 


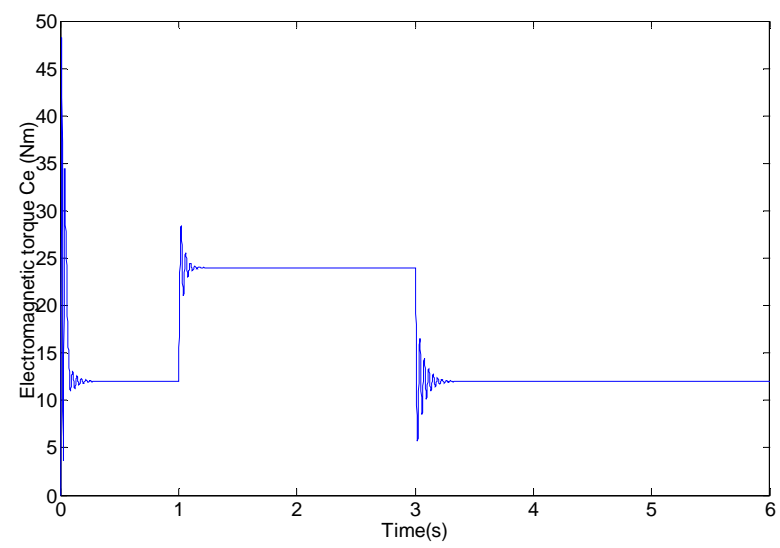

Figure 9. Torque characteristic

The results of simulation are also given for the asynchronous motor is low slip machine; that is, rated torque is developed at synchronous speed as shown in Figure 9. T.c.nwodo [12] presents a large ripple in the torque this can't be remarked in ouir method.

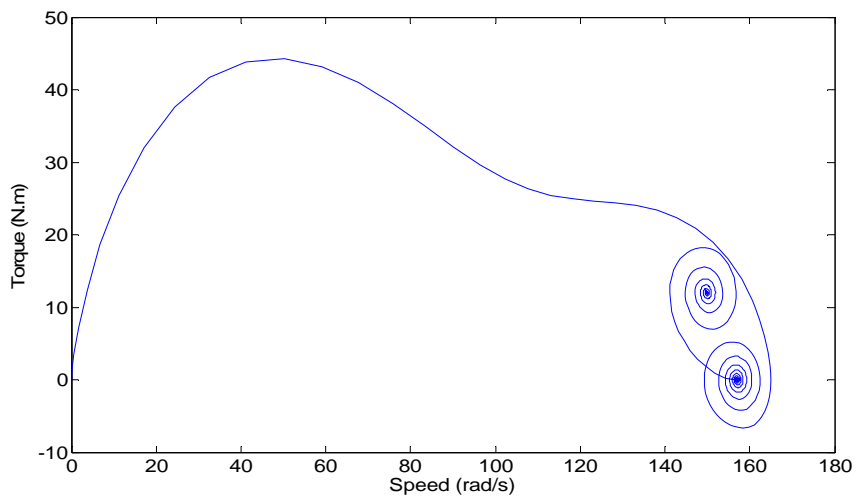

Figure 10. Torque-speed characteristics

Figure 11 shows respectively joule losses of the stator and rotor, they point out that losses vary in the transient until attaining of Pjs at $8000 \mathrm{~W}$ and Pjr at $5000 \mathrm{~W}$ and become stable in permanent area afterwards $0.2 \mathrm{~s}$. To reduce joule losses of the stator is essential to reduce the resistance of the winding. There are two main ways that this can be achieved - either enlarging the wire diameter or increasing the stator length, with several alternatives.
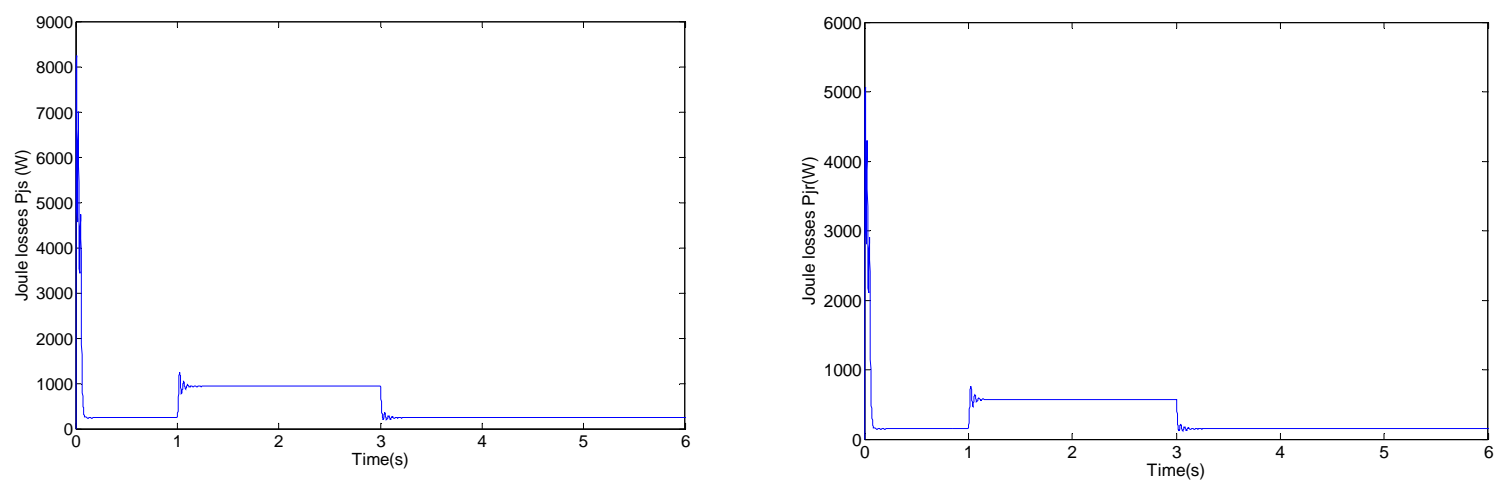

Figure 11. Joule losses in the stator and rotor winding 
Figure 12 shows the flux $\varphi$, which is assumed to vary sinusoidally as function of time (t) after the transient, is expressed in terms of its peak instantaneous value.
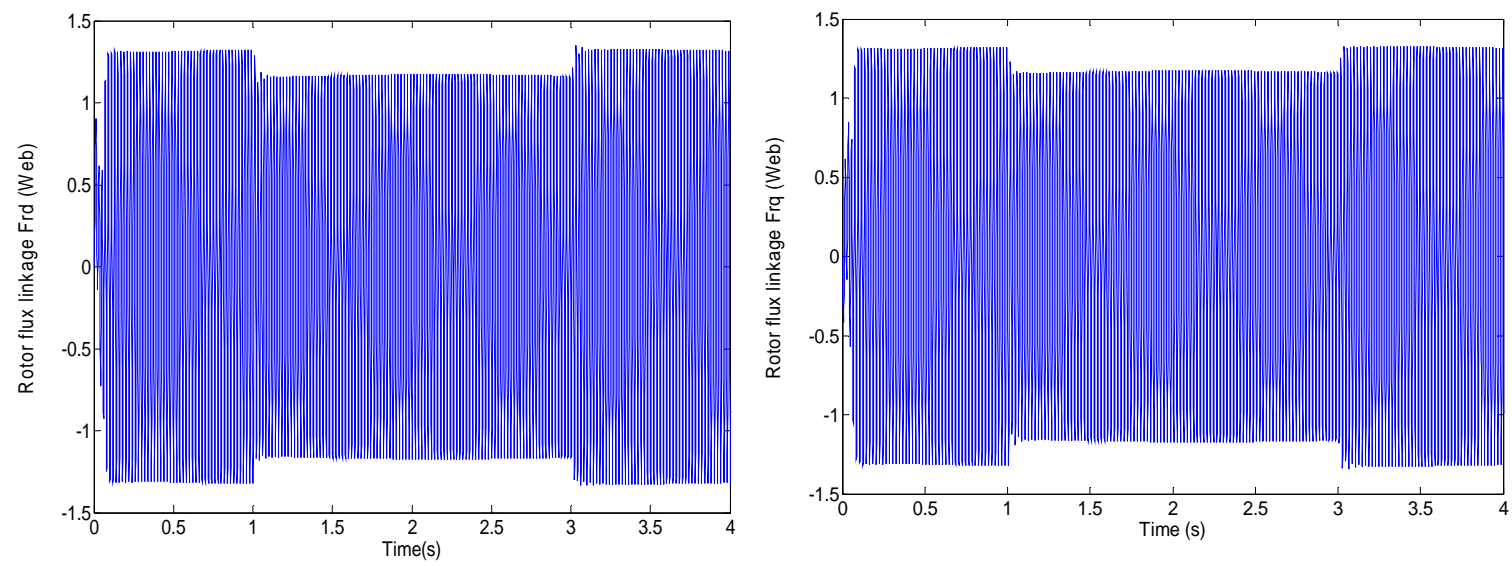

Figure 12. Rotor flux $\varphi$ rd, $\varphi$ rq

Figure 13 shows the efficiency of asynchronous motor, the core losses can be included in efficiency calculations. Since the short-circuited rotor windings have small resistance, a small slip induces a large current in the rotor and produces large torque. At full rated load, slip varies from more than 5\% (Figure 14).

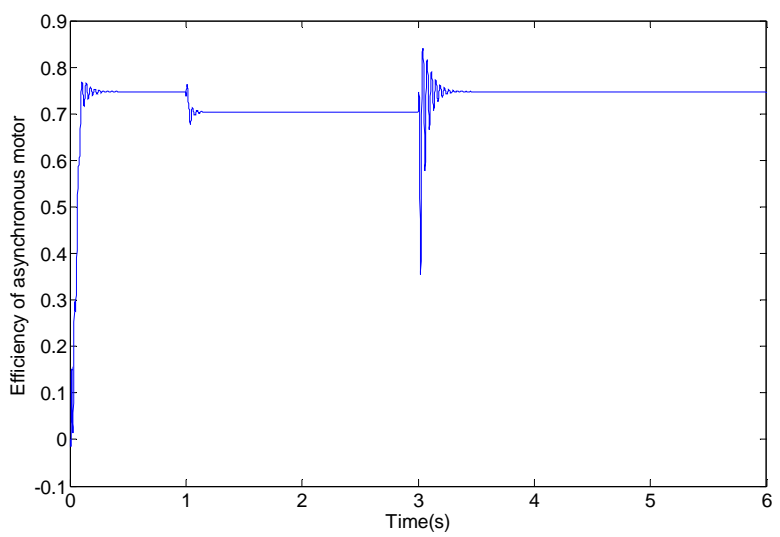

Figure 13. Efficiency of asynchronous motor

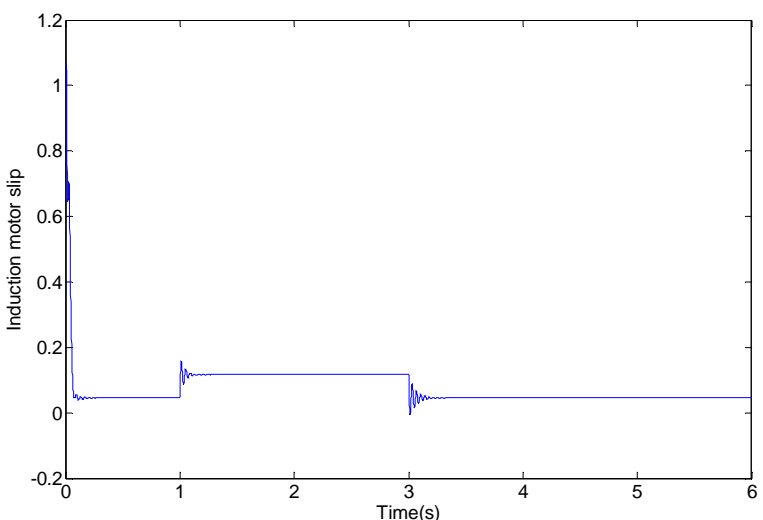

Figure 14. Slip of asynchronous motor

\subsection{Comparison study}

In order to evaluate the modelisation of the asynchronous motor, the following comparison is introduced. In reference [1], Constructional details of various sub-models for the induction motor. The speed and torque responses are illustrated in Figure 8 and 9 according to [1]. In reference [6], the speed and torque responses are illustrated in Figure 5 and 6. It is clear from our results that the speed and torque reponse of investigated method is faster. A motor similar to that used in reference [9] is simulated by the proposed model, where the current is presented in Figure.6, we can remarked that startup time of approximately $0.2 \mathrm{~s}$ and the current is too large in starting motor, it is the real case of an induction machine, which isn't illustrated in reference [9]. The reference [15] presents a large ripple in the torque; this can be remarked from the response of our method, which is maintained constant. In all of references, we can't see the joule lossess; the slip and efficiency but the proposed method presents the all of this behaviours.

\section{CONCLUSION}

This article proposes a methodology for modeling and simulation of an asynchronous motor by Matlab. The developed model is built from simple sub-models. The equations were established based equations demonstrate behavior at steady state of asynchronous machines. As against its simulation is 
difficult, because the model is highly nonlinear, we used the three-phase voltage transformation with two axes to simplify many equations that react the physical behavior of the machine. Through the use of Simulink tool, we have developed the effects of non-linearity in the dynamic performance of induction motor and give the user access to all internal variables getting an overview of the functioning of the machine when starting without load and with an additional charge.

The results obtained demonstrate the correctness of the model developed and are also confirmed from the results published in the bibliography. Thus, the model developed allowed loss control of the asynchronous machine and also the electrical, mechanical and magnetic behavior. These aspects are important for the industrial use of an induction machine. Finally, the simulation results provide insight on choosing the order of the asynchronous machine.

\section{ACKNOWLEDGEMENTS}

This work is supported by the presidency of the University Moulay Ismail, Meknes - Morocco.

\section{REFERENCES}

[1] K. I. Shi, et al., "Modelling and simulation of the three-phase induction motor using Simulink," Int. J. Elect. Enging. Educ, vol. 36, pp. 163-172, 1999.

[2] N. Rahaman and H. V. Govindraju, "Modeling \& Simulation of a Three-Phase Electric Traction Induction Motor Using Matlab Simulink," International Journal of Electrical, Electronics and Computer Systems (IJEECS), vol/issue: 2(5,6), pp. 18-25, 2014.

[3] S. Ayasun and C. Nwankpa, "Induction Motor Tests Using MATLAB/Simulink and Their Integration in to Undergraduate Electric Machinery Courses," IEEE transactions on education, vol/issue: 48(1), 2005.

[4] E. Anbarasu and M. Karthikeyan, "Modeling of Induction Motor and Fault Analysis," International Journal of Engineering Science and Innovative Technology (IJESIT), vol/issue: 2(4), 2013.

[5] E. Delaleau, et al., "Modeling and control of induction motors," Int. J. Appl. Math. Comput. Sci, vol/issue: 11(1), pp. 105-129, 2001.

[6] H. Arabaci and O. Bilgin, "Squirrel Cage of Induction Motors Simulation via Simulink," International Journal of Modeling and Optimization, vol/issue: 2(3), pp. 324-327, 2012.

[7] S. Issac and K. Vanamathi, "Modelling of single Sided Linear Induction Motor by MATLAB/SIMULINK," International Journal of Soft Computing and Engineering, vol/issue: 2(3), pp. 492-494, 2012.

[8] B. Liang A., et al., "Simulation and fault detection of three-phase induction motors," Mathematics and Computers in Simulation, vol/issue: 61(1), pp. 1-15, 2002.

[9] P. M. Palpankar, et al., "A Generalized Dynamic Model of Induction Motor using Simulink," Transactions on Electrical and Electronics Engineering (ITSI-TEEE), vol/issue: 1(5), pp.118-122, 2013.

[10] M. Wieczorek and E. Rosołowski, "Modelling of Induction Motor for Simulation of Internal Faults," Modern Electric Power Systems, vol/issue: 3(9), pp. 29-35, 2010.

[11] M. Arkan, et al., "Modelling and simulation of induction motors with inter-turn faults for diagnostics," Electric Power Systems Research, vol/issue: 75(1), pp. 57-66, 2005.

[12] T. C. Nwodo, "Simulation tools for electrical machines modelling: teaching and research," Nigerian Journal of Technology, vol/issue: 24(1), pp. 33-37, 2015.

[13] S. K. Jain, et al., "Modeling and Simulation of an Induction Motor," International Journal of Engineering Research and Development, vol/issue: 10(4), pp. 57-61, 2014.

[14] R. Singh, et al., "Comparative Study of PWM Control and PI Control of Induction Motor," Bulletin of Electrical Engineering and Informatics, vol/issue: 4(1), pp. 53-58, 2015.

[15] Mohan K. S and Febin Daya J. L, "Machine model based Speed Estimation Schemes for Speed Encoderless Induction Motor Drives: A Survey," Bulletin of Electrical Engineering and Informatics, vol/issue: 4(1), pp. 7-17, 2015 . 